\title{
RESEARCH
}

Open Access

\section{Examining trends in cardiovascular disease mortality across Europe: how does the introduction of a new European Standard Population affect the description of the relative burden of cardiovascular disease?}

Shiva Tadayon ${ }^{1,2}$, Kremlin Wickramasinghe ${ }^{1,3}$ and Nick Townsend ${ }^{1,4^{*}}$ (i)

\begin{abstract}
Background: Some mortality statistics are misleading when comparing between countries due to varying age distributions in their populations. In order to adjust for these differences, age-standardised mortality rates (ASMRs) are often produced. ASMRs allow for comparisons between countries as if both had the same standardised population. We examined whether the updating of the standard population for Europe affected the description of the relative burden between countries in cardiovascular disease (CVD) mortality across the continent.

Methods: Mortality and population data were obtained from the World Health Organization (WHO) mortality database. ASMRs were calculated using the direct method and two European Standard Populations (ESP): 1976 ESP and 2013 ESP. We investigated differences in ASMR76 (calculated using 1976 ESP) and ASMR13 (calculated using 2013 ESP), changes in rankings of countries between the two ASMRs and differences in trends in CVD mortality in each country for the two ASMRs.

Results: CVD rates calculated using the 1976 ESP were on average half the size of rates calculated using the 2013 ESP. Spearman's rank coefficient showed that the ranks of countries by ASMRs calculated using the two ESPs were different for both sexes. Joinpoint analyses showed no difference in the direction of trend between ASMR76 and ASMR13 although differences in the magnitude of the change were found in some countries.

Conclusion: ASMRs are commonly used in studying the epidemiology of a disease. It is crucial that policy makers understand the effect of changes in standard populations on these rates. This includes how populations with different age distributions compare to each other. Similar effects may be seen in other diseases that are also more prevalent in older age groups, such as cancer and dementia.
\end{abstract}

Keywords: Cardiovascular disease, Epidemiology, European Standard Population, Mortality

\footnotetext{
* Correspondence: N.P.Townsend@bath.ac.uk

${ }^{1}$ Centre on Population Approaches for Non-Communicable Disease

Prevention, Nuffield Department of Population Health, University of Oxford,

Oxford, UK

${ }^{4}$ Department for Health, University of Bath, Bath BA2 7AY, UK

Full list of author information is available at the end of the article
}

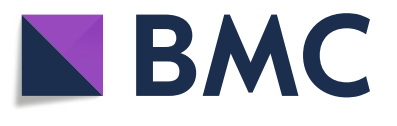

(c) The Author(s). 2019 Open Access This article is distributed under the terms of the Creative Commons Attribution 4.0 International License (http://creativecommons.org/licenses/by/4.0/), which permits unrestricted use, distribution, and reproduction in any medium, provided you give appropriate credit to the original author(s) and the source, provide a link to the Creative Commons license, and indicate if changes were made. The Creative Commons Public Domain Dedication waiver (http://creativecommons.org/publicdomain/zero/1.0/) applies to the data made available in this article, unless otherwise stated. 


\section{Introduction}

Despite large decreases in cardiovascular disease (CVD) mortality within Europe over the last four decades [1-3], CVD remains the leading cause of mortality in the continent [4]. More than 4 million deaths are attributed to CVD in Europe annually, accounting for $46 \%$ of all deaths, with the number of CVD deaths higher in women (2.2 million) than men (1.8 million) [2].

Despite decreasing trends in mortality from CVD found in most European countries, there is great variation in the extent of this decline between countries. For example, 10-year decreases in CVD age-standardised mortality rates (ASMRs) ranged from $1.3 \%$ and $6.3 \%$ for men and women respectively in Kyrgyzstan to $56.5 \%$ and $65.6 \%$ respectively in Kazakhstan [2]. It is no surprise that large inequalities remain across Europe in the relative and absolute burden of CVD [5, 6] with CVD-related mortality generally higher in Central and Eastern Europe [1, 2, 5, 7].

Comparing between countries and sexes can be problematic due to differences in population structure. Since CVD is more common in older age groups, countries or sexes with a greater proportion of older individuals may be expected to suffer a higher proportion of CVD deaths [8]. ASMRs are used to account for some differences in age and population structure and have been used to compare between European countries in the burden of many CVD outcomes, including mortality. ASMRs are calculated by applying age-specific mortality rates for different countries to the same standard population. Rates can differ depending on which standard population is used.

The European Standard Population (ESP) is recommended for the calculation of ASMRs in Europe. However, Eurostat, the statistical office of the European Union, updated the 1976 ESP in 2013 to reflect better the current European population structure that had changed from 1976 due to an increase in life expectancy [9]. The 2013 ESP has greater weighting on older age groups and has an upper limit disaggregated to include age groups of 90 years and older, compared to the 1976 ESP upper age limit of 85 and over [10].

The introduction of the 2013 ESP has been shown to lead to ASMRs in CVD about twice as large as those calculated using the 1976 ESP [2]. This increase may not be the same for all countries and sexes as there is a greater emphasis on older age groups in the 2013 ESP. Those with a greater proportion of older age groups liable to show relatively larger increases. This may change how we view inequalities in CVD mortality within Europe. We know that the change in standard population will change the ASMRs calculated; if this change is uniform across all countries, then the description and presentation of inequalities across Europe are unaffected. However, if this change in standard population leads to heterogeneous changes in ASMRs between countries, this may change the narrative around inequalities in CVD mortality across the continent.

In this study, we aimed to examine how updating the ESP changed the CVD ASMRs calculated for European countries and whether the extent of any relative difference varied by country. We calculated CVD ASMRs for each country and both sexes using both European Standard Populations, ESP13 and ESP76. We examined changes to ASMRs due to the change in ESP and examined changes in the trends in CVD mortality expressed through ASMRs calculated using the 1976 and 2013 ESPs. Joinpoint analysis was used to analyse trends in CVD ASMRs for both ESPs in each country over time and by sex.

\section{Methods}

Data on cause-specific numbers of deaths and population numbers, by sex and in 5-year age groups (up to 85 and over) for European countries were extracted from the WHO global mortality database. The WHO database collates data reported by national authorities based on their civil registration systems and contains data for 51 of 53 European countries. Data for each country were extracted and analysed for the years of 1965 to 2014, where available. Countries were excluded if both population and mortality data for that year were not available (Andorra and Monaco).

Cardiovascular disease as a cause of death was defined according to the following International Classification of Disease codes: ICD-10 (International Classification of Diseases, tenth revision) codes I00-I99; ICD-9 codes 390-459, ICD-8 codes A081-A088 and ICD-7 codes A080-A086. Age and sex-specific mortality rates were calculated and the direct method was used to calculate age-standardised mortality rates for both the ESP76 (ASMR76) and ESP13 (ASMR13). These rates are presented for the 'most recent year', which are related to the most recent data for which both mortality and population data were available.

Countries were ranked by CVD ASMRs with differences in rankings between ASMR76 and ASMR13 examined through Spearman's rank test. All statistical analyses were performed using STATA (version 14.0).

Trends in ASMRs for both ESPs were calculated. Joinpoint Trend Analysis Software (version 4.3.1.0) was used to perform joinpoint regressions to identify periods with statistically distinct log-linear trends in death rates from CVD over time within each age group, by sex and country. We used joinpoint to calculate the average annual percentage change (AAPC) over the entire period of available data and the annual percentage change (APC) for individual trend segments. Segments are identified by inflexion points ('joinpoints') at which there is a significant change 


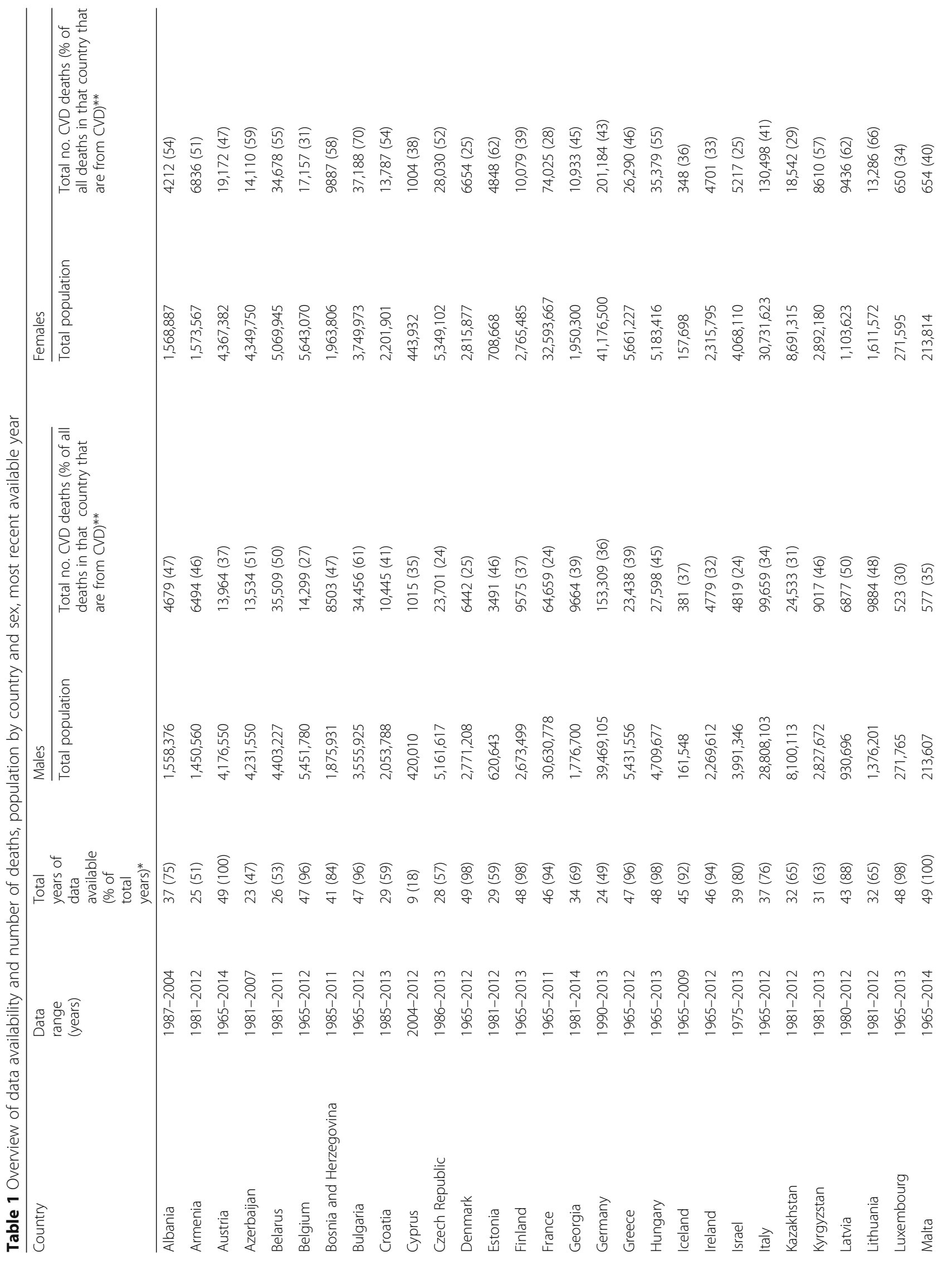




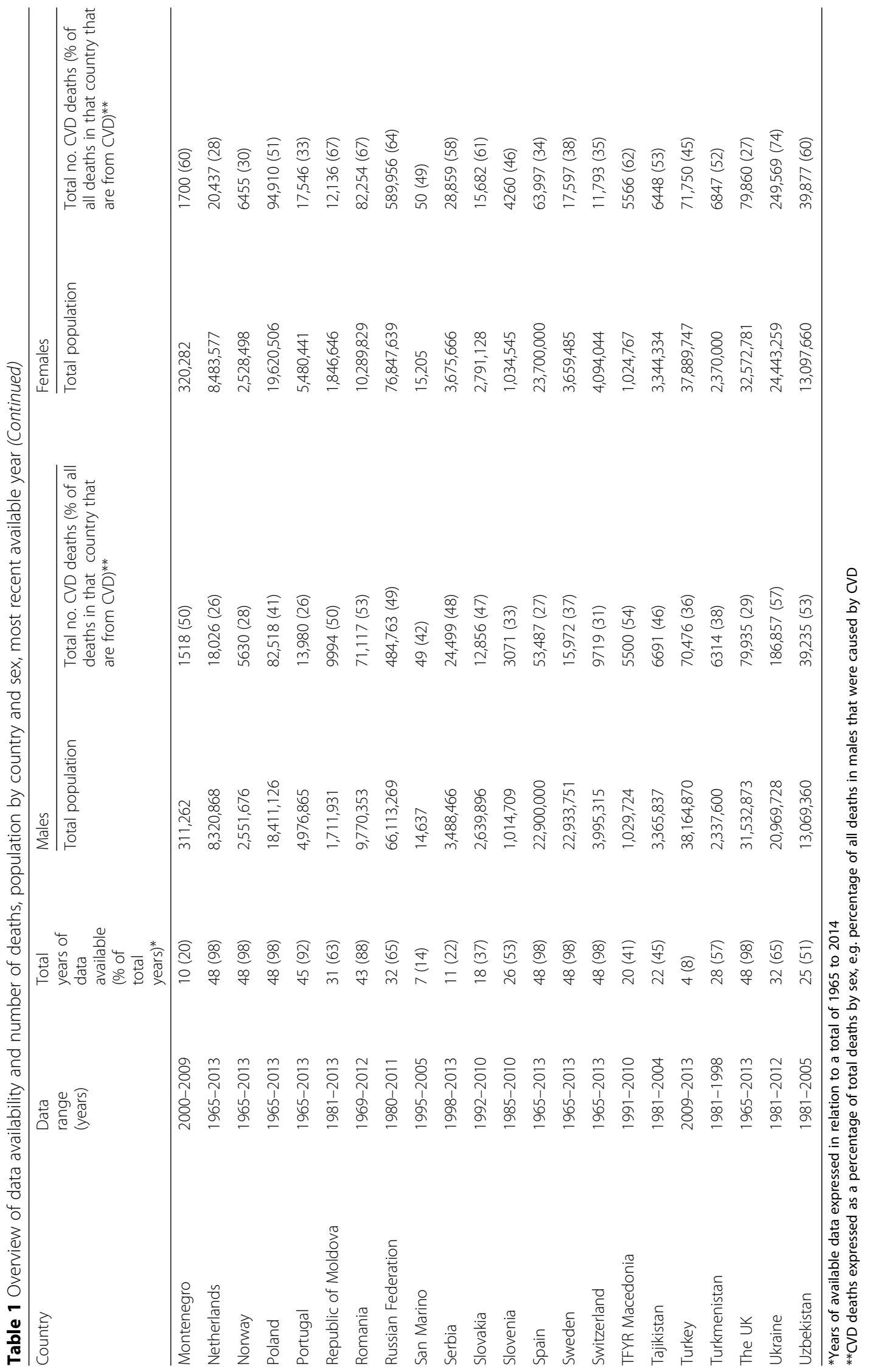




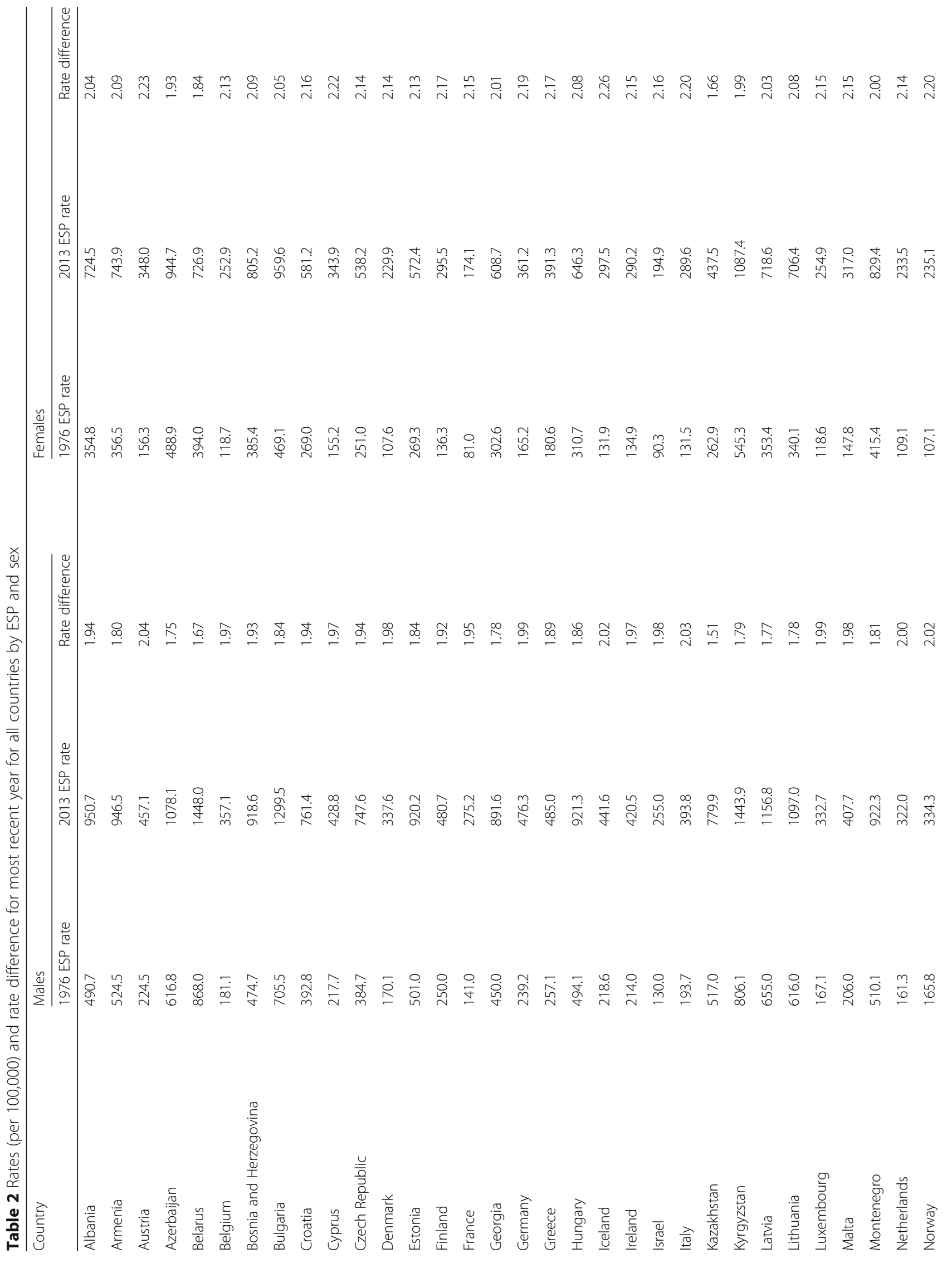




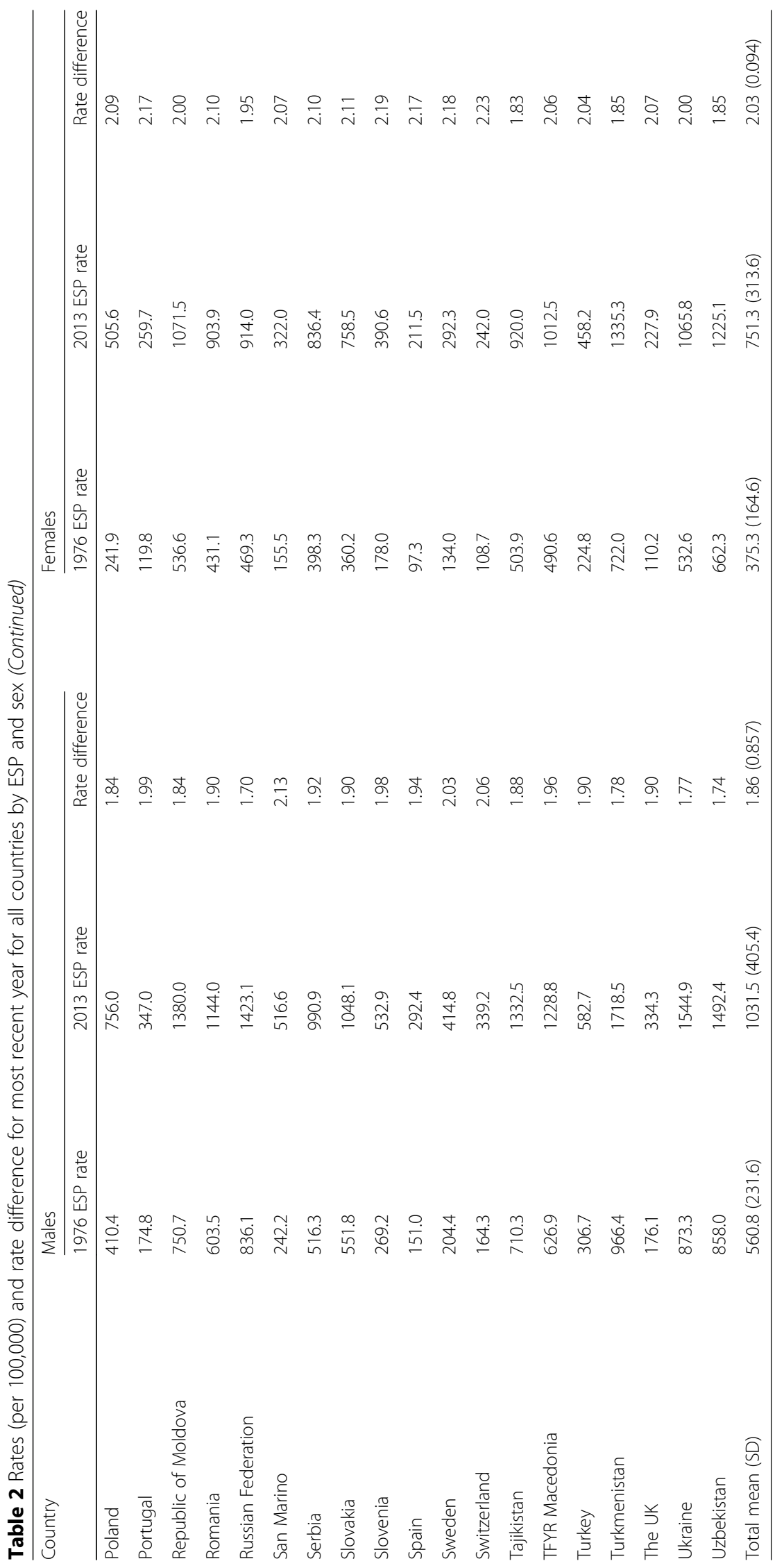


Table 3 Ranking number for countries from lowest to highest cardiovascular disease mortality rates (per 100,000), by latest available year

\begin{tabular}{|c|c|c|c|c|c|c|}
\hline \multirow[t]{2}{*}{ Country } & \multicolumn{2}{|l|}{ Males } & \multirow{2}{*}{$\begin{array}{l}\text { Change } \\
\text { in } \\
\text { ranking }\end{array}$} & \multicolumn{2}{|l|}{ Females } & \multirow{2}{*}{$\begin{array}{l}\text { Change } \\
\text { in } \\
\text { ranking }\end{array}$} \\
\hline & 1976 ESP & 2013 ESP & & 1976 ESP & 2013 ESP & \\
\hline Albania & 36 & 36 & 0 & 36 & 34 & 2 \\
\hline Armenia & 35 & 34 & 1 & 34 & 36 & -2 \\
\hline Austria & 18 & 18 & 0 & 18 & 20 & -2 \\
\hline Azerbaijan & 40 & 38 & 2 & 38 & 44 & -6 \\
\hline Belarus & 49 & 48 & 1 & 48 & 35 & 13 \\
\hline Belgium & 11 & 11 & 0 & 11 & 9 & 2 \\
\hline Bosnia and Herzegovina & 28 & 30 & -2 & 30 & 38 & -8 \\
\hline Bulgaria & 43 & 43 & 0 & 43 & 45 & -2 \\
\hline Croatia & 26 & 27 & -1 & 27 & 29 & -2 \\
\hline Cyprus & 16 & 16 & 0 & 16 & 19 & -3 \\
\hline Czech Republic & 25 & 25 & 0 & 25 & 27 & -2 \\
\hline Denmark & 8 & 8 & 0 & 8 & 5 & 3 \\
\hline Estonia & 31 & 31 & 0 & 31 & 28 & 3 \\
\hline Finland & 21 & 20 & 1 & 20 & 15 & 5 \\
\hline France & 2 & 2 & 0 & 2 & 1 & 1 \\
\hline Georgia & 30 & 29 & 1 & 29 & 30 & -1 \\
\hline Germany & 19 & 19 & 0 & 19 & 21 & -2 \\
\hline Greece & 22 & 21 & 1 & 21 & 23 & -2 \\
\hline Hungary & 29 & 32 & -3 & 32 & 31 & 1 \\
\hline Iceland & 17 & 17 & 0 & 17 & 16 & 1 \\
\hline Ireland & 15 & 15 & 0 & 15 & 13 & 2 \\
\hline Israel & 1 & 1 & 0 & 1 & 2 & -1 \\
\hline Italy & 12 & 12 & 0 & 12 & 12 & 0 \\
\hline Kazakhstan & 34 & 28 & 6 & 28 & 24 & 4 \\
\hline Kyrgyzstan & 46 & 47 & -1 & 47 & 49 & -2 \\
\hline Latvia & 42 & 41 & 1 & 41 & 33 & 8 \\
\hline Lithuania & 39 & 39 & 0 & 39 & 32 & 7 \\
\hline Luxembourg & 7 & 5 & 2 & 5 & 10 & -5 \\
\hline Malta & 14 & 13 & 1 & 13 & 17 & -4 \\
\hline Montenegro & 32 & 33 & -1 & 33 & 39 & -6 \\
\hline Netherlands & 4 & 4 & 0 & 4 & 6 & -2 \\
\hline Norway & 6 & 6 & 0 & 6 & 7 & -1 \\
\hline Poland & 27 & 26 & 1 & 26 & 26 & 0 \\
\hline Portugal & 9 & 10 & -1 & 10 & 11 & -1 \\
\hline Republic of Moldova & 45 & 45 & 0 & 45 & 48 & -3 \\
\hline Romania & 38 & 40 & -2 & 40 & 41 & -1 \\
\hline Russia Federation & 47 & 46 & 1 & 46 & 42 & 4 \\
\hline San Marino & 20 & 22 & -2 & 22 & 18 & 4 \\
\hline Serbia & 33 & 35 & -2 & 35 & 40 & -5 \\
\hline Slovakia & 37 & 37 & 0 & 37 & 37 & 0 \\
\hline Slovenia & 23 & 23 & 0 & 23 & 22 & 1 \\
\hline Spain & 3 & 3 & 0 & 3 & 3 & 0 \\
\hline
\end{tabular}


Table 3 Ranking number for countries from lowest to highest cardiovascular disease mortality rates (per 100,000), by latest available year (Continued)

\begin{tabular}{|c|c|c|c|c|c|c|}
\hline \multirow[t]{2}{*}{ Country } & \multicolumn{2}{|l|}{ Males } & \multirow{2}{*}{$\begin{array}{l}\text { Change } \\
\text { in } \\
\text { ranking }\end{array}$} & \multicolumn{2}{|l|}{ Females } & \multirow{2}{*}{$\begin{array}{l}\text { Change } \\
\text { in } \\
\text { ranking }\end{array}$} \\
\hline & 1976 ESP & 2013 ESP & & 1976 ESP & 2013 ESP & \\
\hline Sweden & 13 & 14 & -1 & 14 & 14 & 0 \\
\hline Switzerland & 5 & 9 & -4 & 9 & 8 & 1 \\
\hline Tajikistan & 44 & 44 & 0 & 44 & 43 & 1 \\
\hline TFYR Macedonia & 41 & 42 & -1 & 42 & 46 & -4 \\
\hline Turkey & 24 & 24 & 0 & 24 & 25 & -1 \\
\hline Turkmenistan & 51 & 51 & 0 & 51 & 51 & 0 \\
\hline The UK & 10 & 7 & 3 & 7 & 4 & 3 \\
\hline Ukraine & 50 & 50 & 0 & 50 & 47 & 3 \\
\hline Uzbekistan & 48 & 49 & -1 & 49 & 50 & -1 \\
\hline
\end{tabular}

*1 = lowest, 51 = highest

in trends, using a series of permutation tests, with Bonferroni adjustment for multiple comparisons. The changes in trend may include any change in intensity, but could include a change in direction. We used a two-sided significance level set at $P<0.05$ for all tests. Significant joinponts for each country by sex (maximum of 5) were determined using a log-linear model, and the annual percentage change (APC) within each segment calculated. The use of a log-linear model enables the analysis of constant percentage (rather than absolute) change in prevalence over time. Plateauing of the most recent trend for a country was defined as the trend in the most recent segments showing either a less steep decline than the preceding segment, no significant difference to zero, or an increase. Joinpoint segments were compared between ASMRs from both ESPs to examine differences in trends.

\section{Results}

On average, 35 years of data were available for all countries. Complete data for all 49 years were only available for two countries, Malta and Austria, with 30 years or more of data available for $33(64.7 \%)$ countries. Less than 10 years of data were available for three countries: Cyprus (9 years), San Marino (7 years) and Turkey (4 years). The number of total CVD deaths was greater in women than men in 42 out of 51 countries for the most recent available year. Furthermore, a higher percentage of total deaths that were from CVD were found in women in 48 out of 51 countries (Table 1 ).

CVD rates calculated using the 1976 ESP were on average half the size of rates calculated using the 2013 ESP (mean rate difference $=1.95 ; P<0.001$ ). The mean rate difference was 1.86 for men and 2.03 for women. ASMR13s were more than twice as large as ASMR76s in males for eight countries (Austria, Iceland, Italy, Kazakhstan, Netherlands, Norway, San Marino, Sweden, and Switzerland). In females, ASMR13s were more than twice as large as ASMR76s for more than three quarters of countries (Table 2).

Mean CVD rates calculated using both ESPs were significantly lower in females than males (mean rate males, ASMR76 $=560.8$, ASMR13 $=1031.5$; mean rate females, ASMR76 = 375.3, ASMR13 = 751.3, $P<0.001$ ), but females had a significantly greater proportional difference in rates when comparing the ASMR76s and ASMR13s (mean rate difference; males $=1.86$, females $=2.03, P<0.001$ ) . Spearman's rank coefficient showed that ranks of countries by ASMRs calculated using the two ESPs were different for both sexes (Spearman's rho for men 0.995, $P$ $<0.001$; Spearman's rho for women 0.97, $P<0.001$ ).

The largest changes in ranking were found for males in Kazakhstan which was six places lower when the ranking was compared between ASMR13 and ASMR76. In women, Ukraine was four places lower. In both sexes, Central Asian and Eastern European countries moved the most number of ranked places. In men, Central Asian and Eastern European countries generally moved down the ranking, and for women, these countries generally moved up. For both sexes, the top two and bottom three countries remained the same for rates calculated using both ESP (Table 3).

A majority of countries in both sexes showed a negative ASMR trend calculated using both ESPs. Joinpoint analyses showed no difference in the direction of trend between ASMRs. There were four countries (Albania, Slovenia, Tajikistan, and Turkey) in men and eight countries (Azerbaijan, Belarus, Montenegro, San Marino, Serbia, Slovakia, Slovenia, and Turkey) in women that have a continuous linear trend (no joinpoints identified).

In men, seven countries (San Marino, Austria, Belarus, Azerbaijan, Lithuania, Romania, and Hungary) had a greater decrease in the trend for ASMR13 than ASMR76. This was found in three countries for women (Belarus, Latvia, and Russia). A greater increase in trend in ASMR13 


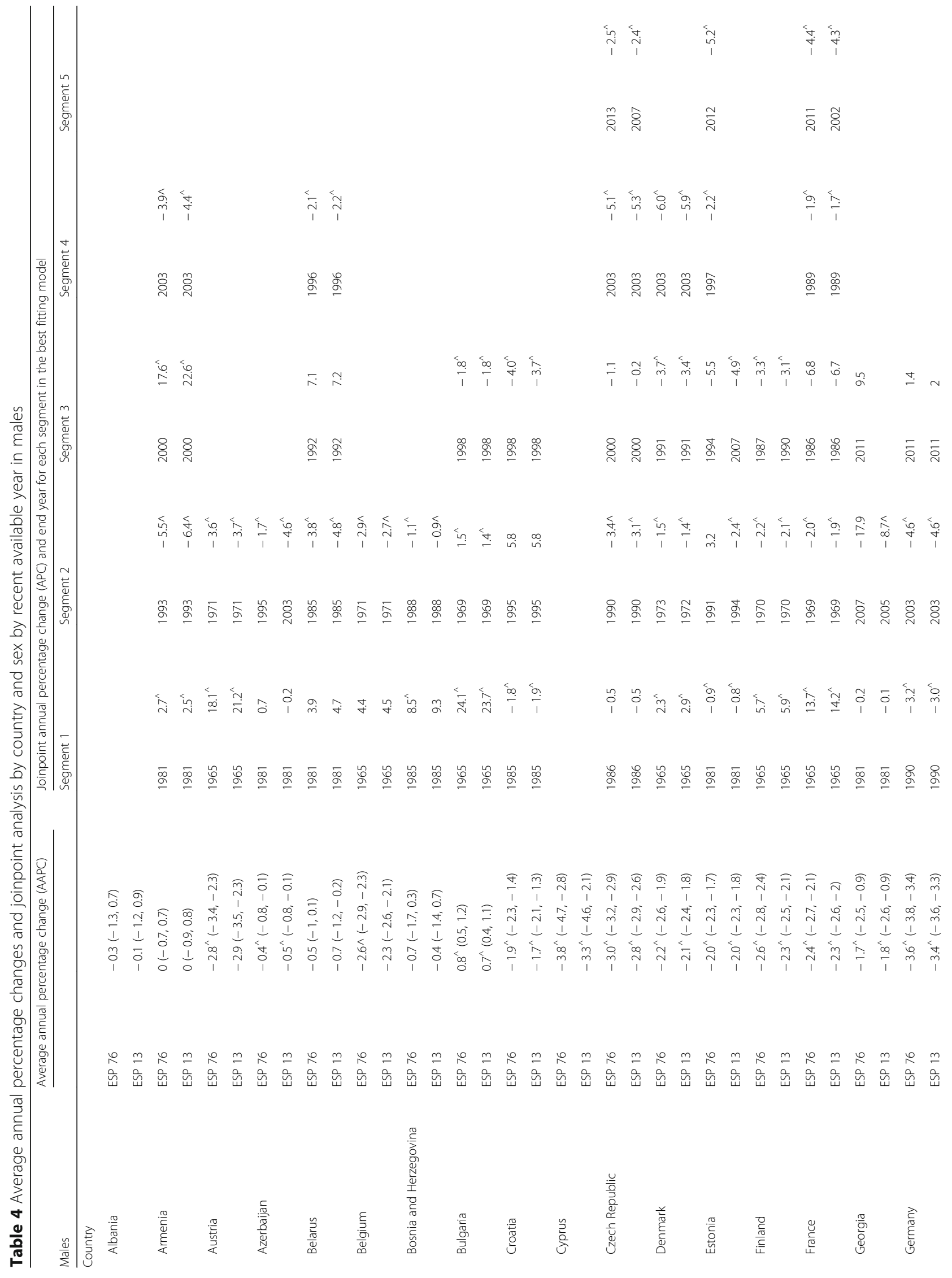




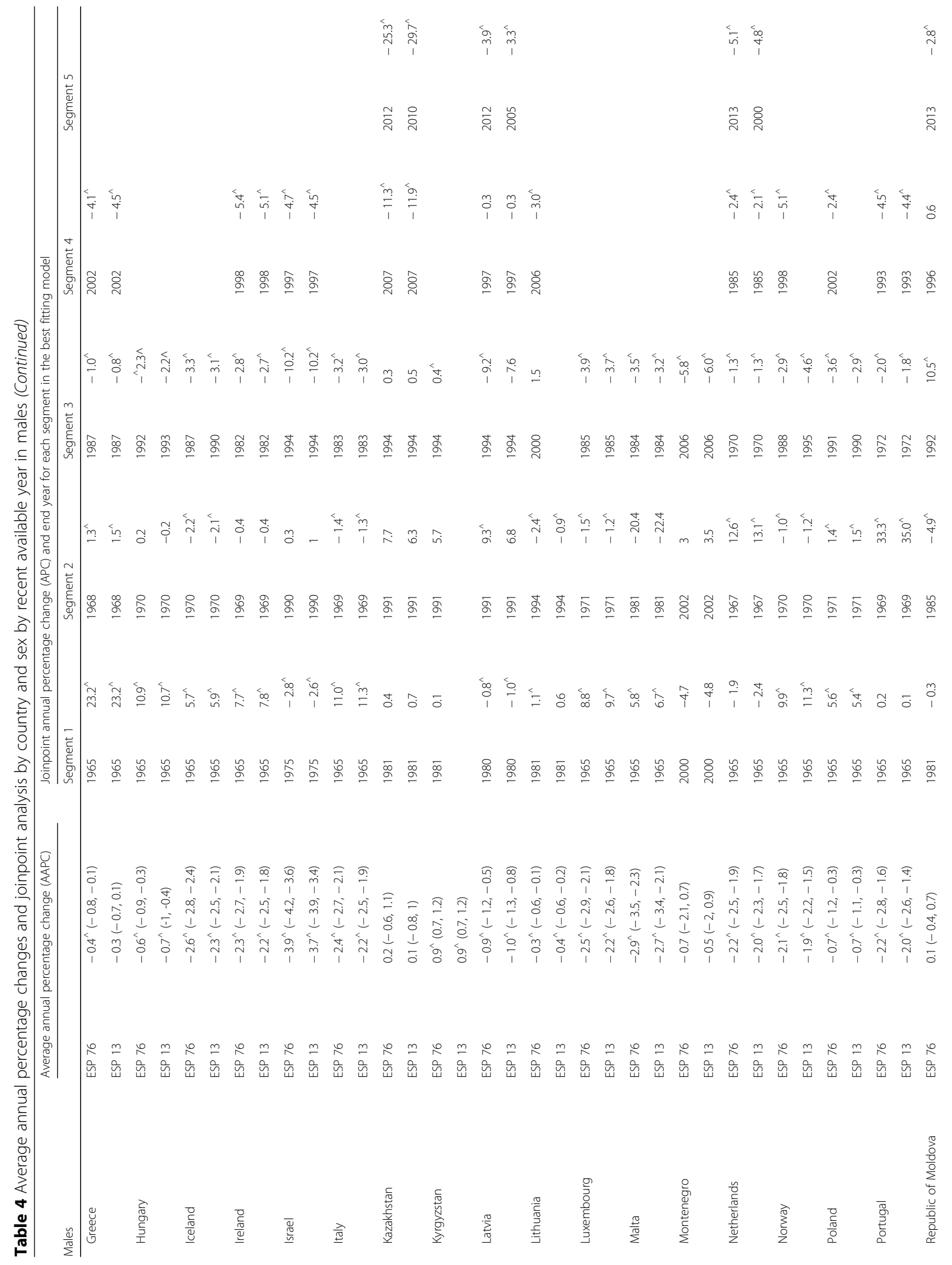




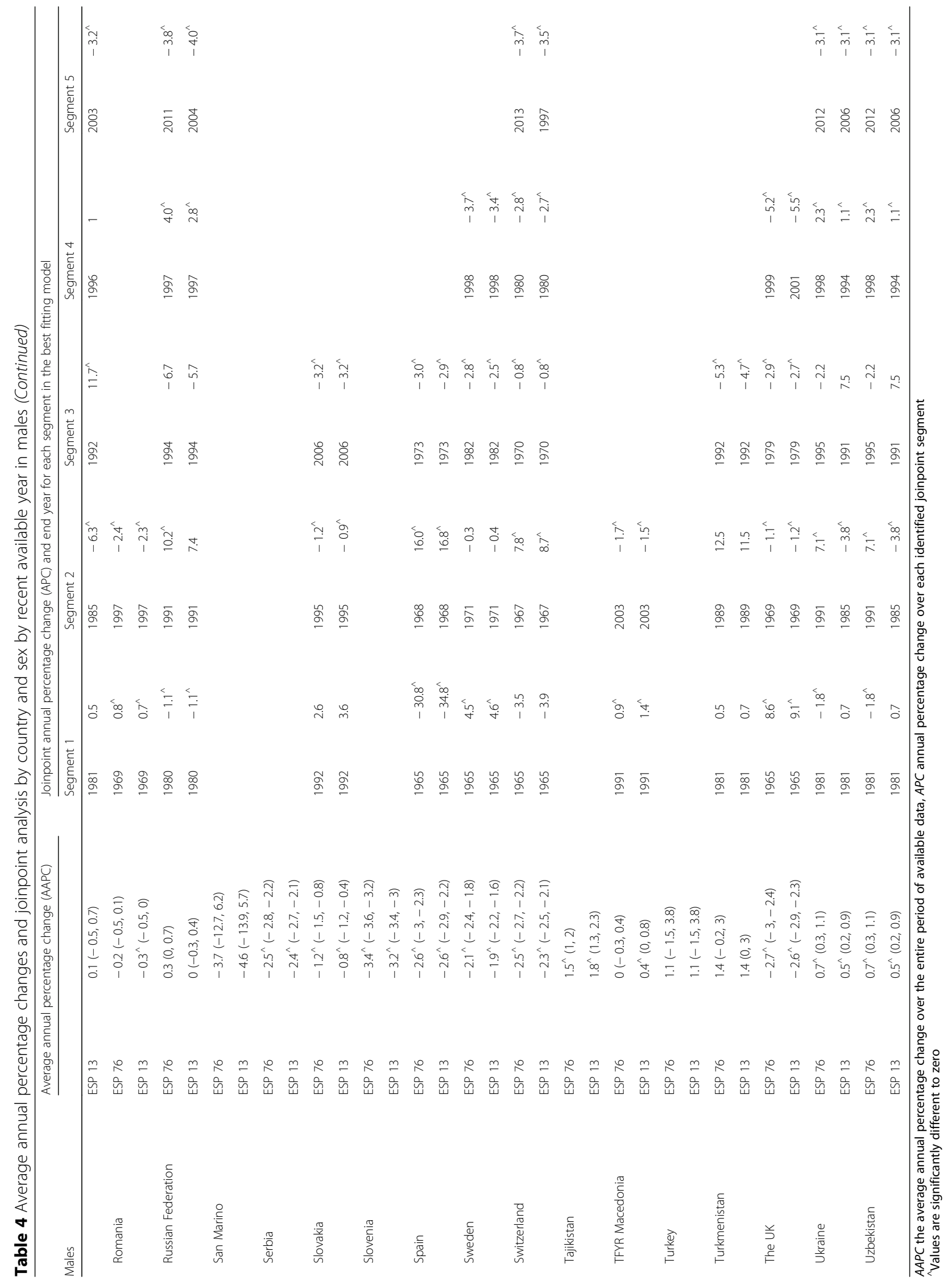




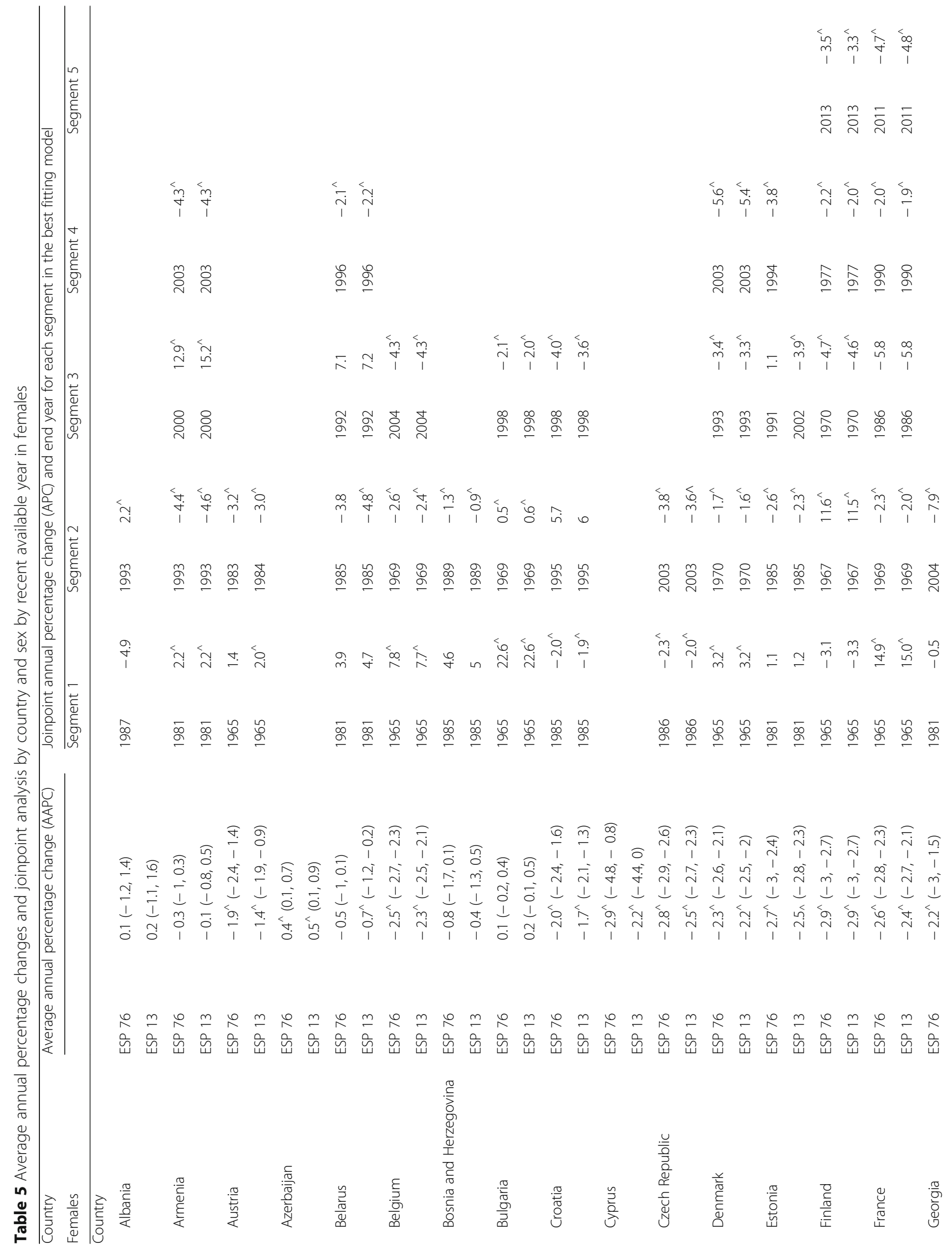




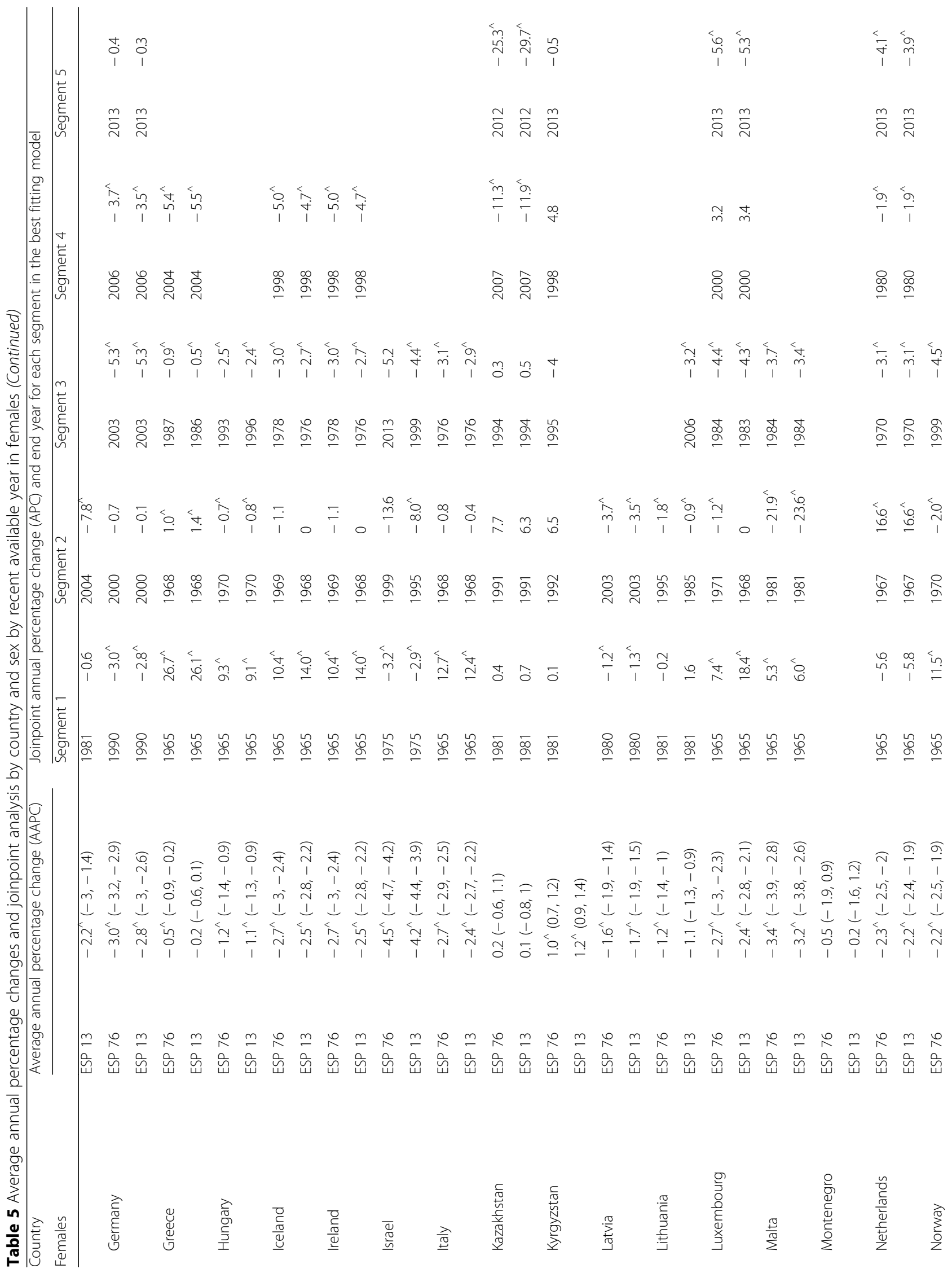




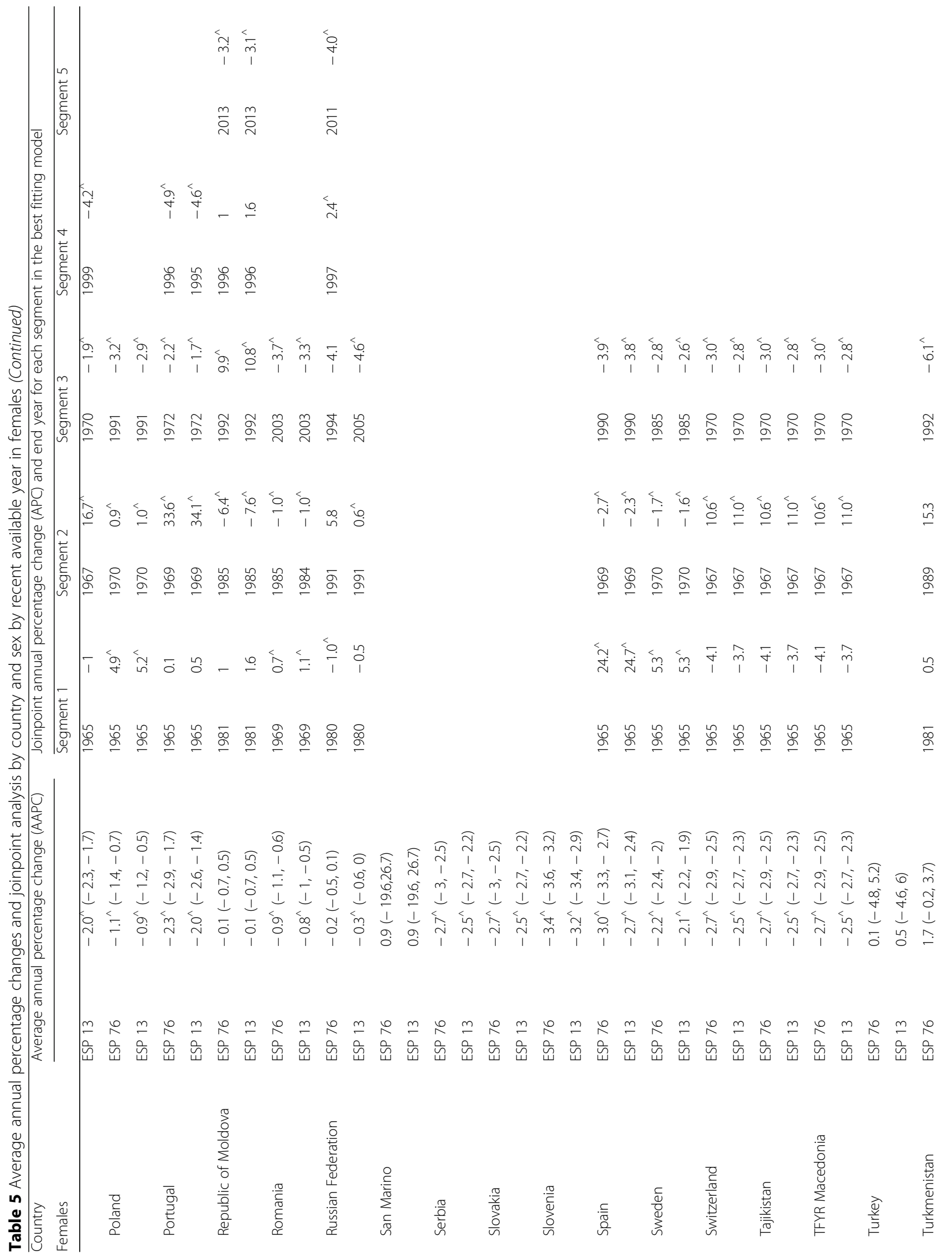




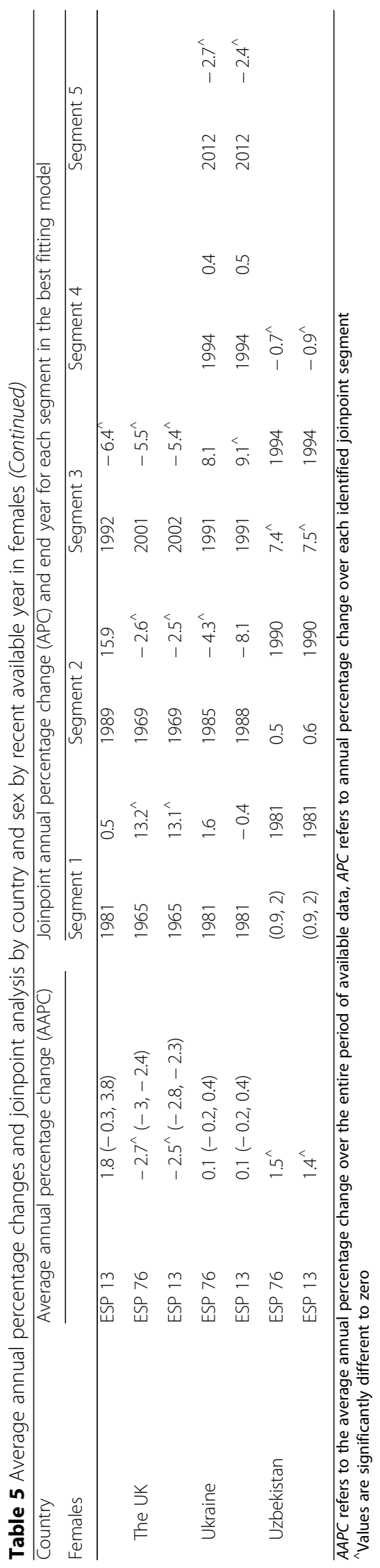


than ASMR76 was found in six countries for women (Albania, Bulgaria, Azerbaijan, Turkey, Kyrgyzstan, and Turkmenistan) and in one country for men (TFYR Macedonia). Four countries (Bulgaria, Russian Federation, Ukraine, and Uzbekistan) had a greater increase in trend for ASMR76 than ASMR13 in men and two in women (Kazakhstan and Uzbekistan) (Table 4).

Differences in the number of joinpoint segments between rates from both ESPs were found for five countries in men (Georgia, Lithuania, Norway, and Poland) and four countries (Albania, Estonia, Kyrgyzstan, and Lithuania) in women. A number of countries showed a plateau in recent trends, as defined by the most recent segment showing either a less steep decline than the preceding segment, no significant difference to zero, or an increase. These plateaus were identified at all times in trends of both ASMRs except for men in Georgia amongst whom a plateau found in the trend of ASMR76 was not found when using ASMR13 (Table 5).

\section{Discussion}

The 2013 ESP changes the relative burden of CVD mortality rates for European countries by sex. The 1976 ESP rates are half as high as those calculated using 2013 ESP in countries for both sexes, and the ranking of countries by CVD ASMR changed when calculating ASMRs using the different standard populations. Despite largely similar trends between ASMR13 and ASMR76 for all countries by sex, there were some differences in trends in ASMRs calculated using different ESPs.

Joinpoint analyses allowed us to compare trends in the $\log$ of ASMRs calculated using the old and new ESPs. This demonstrated that for most countries the direction and intensity of the trend in the two ASMRs were similar, although some differences were apparent. In particular, a number of countries showed a difference in the intensity of the trend over the entire period, when comparing ESP76 to ESP13, although no country was found to have a change in the direction of the trend for either sex. Differences in intensity were more pronounced in countries when comparing the most recent trend, with one country demonstrating a change in the direction of the most recent segment.

Limitations of this research are that there is a variability of global coverage and data quality [11]. Developed countries use the vital record system whereas developing countries use verbal autopsy, which are generally weaker and not standardised $[12,13]$. Furthermore, the results in this study may not be generalizable to countries outside of the WHO Europe Member States. However, findings are representable and internally valid because data were comparable between ESPs since the same data were used.

To our knowledge, this is the first paper to investigate trends in CVD mortality for all European countries. It is also the first to compare ASMRs calculated using ESP13 and ESP76 [2]. Our finding that ASMR76 were half as large as ASMR13s was similar to previous work investigating deaths from coronary heart disease (CHD) rather than CVD as done here [2]. We found no paper that had investigated the difference between trends in ASMRs calculated using ESP13 and ESP76 in total CVD or subtype, although trends in CVD agreed with previous analysis on trends in CHD ASMRs [11] in most countries. Differences in results between studies show a decrease in CHD ASMR in Bulgaria found in the previous [11] compared to an increase in CVD ASMR in the present study. These differences may be due to garbage codes, defined as incomplete registration of death and sex/age in the mortality data for CVD [14]. The WHO reported that Bulgaria had a large amount of garbage codes included for subgroups in CVD [15].

Such changes in standard populations can be confusing for policy makers and public alike, unless clarity is provided in the effect of such changes. We have demonstrated in this paper that the relative description of the burden of CVD mortality between countries occurs when changing the standard population used to calculate age-standardised rates. In addition, in some countries, the intensity and, in one country, the direction, of the most recent trend in CVD ASMRs was altered by the introduction of a new standard population, despite no change in the mortality and population data used to calculate them. Such changes can be misleading and care must be taken not to compare between analyses using different standard populations. ASMRs produce an estimate of mortality that relates to a standard population; this means it is only a useful measure when used comparatively between estimates using the same population. Rates calculated using the actual population are better when calculating an absolute mortality measure. This means that ASMRs can prove confusing, such that there is merit in adopting a standard population that is as representative of the actual population as possible. The most recent ESP (2013) was introduced to better reflect the contemporary population distribution of Europe, so this remains the most suitable ESP for the calculation of standardised rates; it must be noted, however, that this change may alter how we discuss the relative burden of CVD mortality across the continent and in some cases within countries.

\section{Conclusion}

Age-standardised rates are commonly used in studying the epidemiology of a disease. Although changing the standard population will change the rates, this paper also shows that it may change the relative burden of disease when countries or subgroups are compared to each other, despite using the same mortality data. It is crucial 
that policy makers understand the effect of changes in standard populations on these comparisons. Similar effects as those found in CVD in Europe, due to the change in the European Standard Population, may be seen in other diseases that are also more prevalent in older age groups, such as cancer and dementia.

\section{Abbreviations}

ASMR: Age-standardised mortality rates; ASMR13: Age-standardised mortality rates calculated using the 2013 European Standard Population;

ASMR76: Age-standardised mortality rates calculated using the 1976

European Standard Population; CHD: Coronary heart disease:

CVD: Cardiovascular disease; ESP: European Standard Population; ESP13: 2013 European Standard Population; ESP76: 1976 European Standard Population; ICD: International Classification of Disease; UK: United Kingdom; WHO: World Health Organization

\section{Acknowledgements}

Not applicable

\section{Authors' contributions}

ST extracted the data, performed the data analysis and produced a first draft of the paper. NT and KW conceptualised and designed the project, and they also assisted on all aspects including data extraction, analysis and drafting the paper. All authors read and approved the final manuscript.

\section{Funding}

KW and NT were funded by the British Heart Foundation (grant URN: 006/ P\&C/CORE/2013/OXFSTATS). No other funding was received for this work.

\section{Availability of data and materials}

The datasets generated and/or analysed during the current study are available in the European Detailed Mortality Database from the World Health Organization Regional Office for Europe repository: [https://gateway.euro. who.int/en/datasets/european-mortality-database/]

\section{Ethics approval and consent to participate}

Not applicable

\section{Consent for publication}

Not applicable

\section{Competing interests}

The authors declare that they have no competing interests.

\section{Author details}

${ }^{1}$ Centre on Population Approaches for Non-Communicable Disease Prevention, Nuffield Department of Population Health, University of Oxford, Oxford, UK. ${ }^{2}$ UCLA Comprehensive Vascular Neurology Program, Department of Neurology, University of California at Los Angeles, 710 Westwood Plaza, Los Angeles, CA 90095-17693, USA. ${ }^{3}$ World Health Organization European Office for Prevention and Control of Noncommunicable Diseases (NCD Office), Moscow, Russian Federation. ${ }^{4}$ Department for Health, University of Bath, Bath BA2 7AY, UK.

Received: 28 March 2018 Accepted: 8 May 2019

Published online: 30 May 2019

\section{References}

1. Levi F, Lucchini F, Negri E, Vecchia CL. Trends in mortality from cardiovascular and cerebrovascular diseases in Europe and other areas of the world. Heart. 2003;88:119-24.

2. Townsend N, Nichols M, Scarborough P, Rayner M. Cardiovascular disease in Europe 2016: epidemiological update. Eur Heart J. 2016;0:1-14.

3. Wilkins E, Wilson L, Wickramasinghe K, Bhatnagar P, Leal J, LuengoFernandez R, Burns R, Rayner M, Townsend N. European Cardiovascular Disease Statistics 2017. European Heart Network, Brussels; 2017.

4. Evans J. Implementing the 2013 European Standard Population: the impact of selected upper age limits on mortality. London: Office for National Statistics; 2014. www.ons.gov.uk\%2Fons\%2Fguide-method\%2Fuser-
guidance\%2Fhealth-and-life-events\%2Frevised-european-standardpopulation-2013--2013-esp-\%2Fimpact-of-varying-the-2013-esp-upper-agelimit-on-mortality-statistics.doc\&usg=AOvVaw15m0tzEPMrg7CGAPZ5VVZq. Accessed 15 July 2016

5. Niederlaender E. Causes of death in the EU. In: Statistics in focus. European Communities. Luxembourg: Office for Official Publications of the European Communities; 2006. http://ec.europa.eu/eurostat/documents/3433488/ 5440941/KS-NK-06-010-EN.PDF/2a6372ce-2b38-4b2a-bdb1-0de9cd48fa5c. Accessed 15 July 2016

6. Vujcic IS, Sipetic SB, Dubljanin ES, Vlajinac HD. Trends in mortality rates from coronary heart disease in Belgrade (Serbia) during the period 1990-2010: a joinpoint regression analysis. BMC Cardiovasc Disord. 2013;13:112.

7. Sans $\mathrm{S}$, Kestoloot H, Force DKBOTT. The burden of cardiovascular diseases mortality in Europe. Eur Heart J. 1997;18:1231-48.

8. Yazadanyar A, Newman AB. The burden of cardiovascular disease in the elderly: morbidity, mortality, and costs. Clin Geriatr Med. 2009;25(4):563-vii https://doi.org/10.1016/j.cger.2009.07.007.

9. Eurostat EC. Revision of the European Standard Population. Report of Eurostat's task force. Luxembourg: Publications Office of the European Union; 2013. http://ec.europa.eu/eurostat/documents/3859598/5926869/KSRA-13-028-EN.PDF/e713fa79-1add-44e8-b23d-5e8fa09b3f8f Accessed 17 July

10. Olubenga O. The impact of calculating mortality rates using the 2013 European Standard Population on causes of death. London: Office for National Statistics; 2013

11. Nichols M, Townsend N, Scarborough P, Rayner M. Trends in age-specific coronary heart disease mortality in the European Union over three decades: 1980-2009. Eur Heart J. 2013;34:3017-27.

12. Pagidipati NJ, Gaziano TA. Estimating deaths from cardiovascular disease: a review of global methodologies of mortality measurement. Circulation. 2013;127:749-56.

13. Setal PW, Sankoh O, Roa C, Velkoff VA, Mathers C, Gonghuan Y, Hemed Y, Jha P, Lopez AD. Sample registration of vital events with verbal autopsy: a renewed commitment to measuring and monitoring vital statistics. Bull World Health Organ. 2005;83:611-7.

14. WHO. WHO methods and data sources for global causes of death 20002011. Geneva: Department of Health Statistics and Information Systems, WHO; 2013. http://www.who.int/healthinfo/statistics/GHE_TR2013-3_COD_ MethodsFinal.pdf. Accessed 25 June 2016

15. WHO. European detailed mortality database. Copenhagen: World Health Organization Regional Office for Europe; 2015. https://gateway.euro.who.int/ en/datasets/european-mortality-database/. Accessed 25 June 2016

\section{Publisher's Note}

Springer Nature remains neutral with regard to jurisdictional claims in published maps and institutional affiliations.

Ready to submit your research? Choose BMC and benefit from:

- fast, convenient online submission

- thorough peer review by experienced researchers in your field

- rapid publication on acceptance

- support for research data, including large and complex data types

- gold Open Access which fosters wider collaboration and increased citations

- maximum visibility for your research: over $100 \mathrm{M}$ website views per year

At $\mathrm{BMC}$, research is always in progress.

Learn more biomedcentral.com/submission 